\title{
ORIENTAÇÃO EMPREENDEDORA INTERNACIONAL NAS EMPRESAS DO AERODESPORTO
}

Ricardo Raats ${ }^{1}$

Patricia Viveiros De Castro Krakauer ${ }^{2}$

\footnotetext{
${ }^{1}$ FACCAMP

${ }^{2}$ FACCAMP Faculdade Campo Limpo Paulista
} 


\section{ORIENTAÇÃO EMPREENDEDORA INTERNACIONAL NAS EMPRESAS DO AERODESPORTO}

Resumo: O estudo tem como objetivo analisar as práticas de orientação empreendedora internacional nas empresas exportadoras do aerodesporto brasileiro. Explora-se de forma qualitativa os conteúdos de temas sobre empreendedorismo internacional num estudo de caso múltiplo com quatro novos empreendimentos internacionais. Os resultados apresentam diferentes intensidades das características originais do conceito de orientação empreendedora mais propenso à inovação, proatividade e assunção de riscos; todavia, diferenças nas dimensões de agressividade competitiva e de autonomia presentes nos negócios internacionais das empresas amostradas, exemplificam reflexos da precoce internacionalização na cultura organizacional de cada caso quando evidenciam limitações e movimentos de desinternacionalização por causa de idade, inexperiência, restrição de recursos, e acesso limitado a redes em mercados com dinâmica inovadora e de alto risco para a sobrevivência de suas organizações. Justifica-se a realização da pesquisa pela aplicabilidade em negócios que buscam estabelecer a orientação empreendedora internacional como opção estratégica para suas ações empreendedoras internacionais.

Palavras-chave: Internacionalização. Empreendedorismo Internacional. Orientação Empreendedora.

\section{Introdução}

O estudo da Orientação Empreendedora Internacional (OEI) é capaz de caracterizar ações de internacionalização de empresas, interpretadas como comportamento empreendedor das organizações que atuam em ambientes internacionais. Covin e Miller (2014), sugerem a necessidade expressa na Academia de se aplicar as dimensões da Orientação Empreendedora $(\mathrm{OE})$, dentro do domínio do Empreendedorismo Internacional (EI), com o propósito de se compreender como influenciam o potencial de expansão internacional de empresas.

Dentro da literatura de EI, este estudo se apoia nas revisões bibliométricas de Peiris, Akoorie e Sinha (2012); e Martens et al. (2016), para entender como as pesquisas de OE se relacionam com a literatura de processos de internacionalização de empresas, uma vez que esses estudos resumem o desenvolvimento das duas áreas de pesquisa, ambas conformadas por autores de negócios internacionais (ZAHRA; GARVIS, 2000; KNIGHT; KIM, 2009; COVIELLO; MCDOUGALL; OVIATT, 2011; SLEVIN; TERJESEN, 2011; COVIN; WALES, 2012; CAVUSGIL; KNIGHT, 2015; COVIELLO, 2015).

Ao identificar temas chaves no campo de OE adaptados ao contexto das empresas exportadoras do aerodesporto, contribui-se para entender os conceitos aplicados à prática

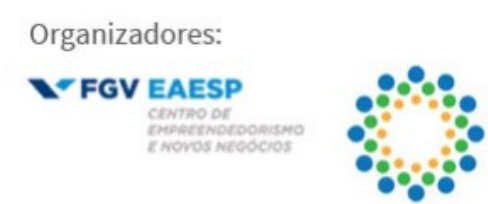


organizacional, dado que o conceito de OE é por muitas vezes tratado sob diferentes aspectos: orientação, intensidade, estilo, postura, propensão, predisposição e empreendedorismo corporativo (COVIN; WALES, 2012). Assim, ao incluírem nas discussões de EI a abordagem de OE, alguns autores exploram OEI como uma aplicação do construto OE a uma realidade internacional (KNIGHT, 2001), enquanto outros consideram uma abordagem enfocando por exemplo exportação, mercado e operações internacionais como um constructo diferente, ou seja, OEI (KNIGHT; CAVUSGIL, 2004; KUIVALAINEN; SUNDQVIST; SERVAIS, 2007; COVIN; MILLER, 2014). De acordo com os estudos de Slevin e Terjesen (2011), a exposição a novos mercados internacionais, como é necessário para reivindicar a existência de uma OEI, é um resultado organizacional e não uma característica pessoal. Dentro de uma visão de EI, o constructo da OEI é um conceito multidimensional considerado tanto para indivíduos como para organizações, que permite identificar como as oportunidades de internacionalização são operacionalizadas pelas empresas, sendo que facilita a compreensão sobre comportamentos competitivos praticados pela gestão das empresas em sua busca por mercados regionais e globais (COVIN; WALES, 2012; COVIN; MILLER, 2014; WACH, 2015)

As dimensões que compõem a OEI foram inicialmente analisadas por uma abordagem multidimensional, conforme sugerem os artigos de Wach (2015), e Wales (2016). Emprega-se a interpretação de Lumpkin e Dess (1996): "OE refere-se aos processos, práticas e atividades de tomada de decisão que levam a uma nova entrada", além de agregar a interpretação de Knight e Cavusgil (2004): "a inovação e a proatividade da empresa na busca de mercados internacionais", permitindo uma abordagem interdisciplinar entre negócios internacionais, empreendedorismo, marketing e gestão (CAVUSGIL; KNIGHT, 2015). Complementarmente, os atributos comportamentais das empresas, identificados nas dimensões de agressividade competitiva e autonomia, também foram observados por meio das ações internacionais em ambientes de incertezas (SCHWEIZER; JOHANSON; VAHLNE, 2010).

Wach (2015) resume o constructo de OEI com escala multidimensional como capaz de predizer mudanças no mercado, pois ajuda a entender práticas de identificação e desenvolvimento de oportunidades (COVIN; SLEVIN, 1989), o emprego da criatividade em processos e produtos (DESS; LUMPKIN, 2005), a busca por soluções inovadoras (KNIGHT, 2001), e tomada de decisões em projetos de risco elevado (MILLER; FRIESEN, 1984), pois exibe agressividade competitiva (KNIGHT, 2001), e favorece atividades humanas independentes ou autonomias entre departamentos nas empresas (LUMPKIN; DESS, 1996).

Espera se que o constructo de OEI seja aplicável e relevante aos empreendedores internacionais, apenas no sentido de que seus empreendimentos exibam intensidades variadas desses atributos, identificados como disposições comportamentais dos gestores ou proprietários das organizações com estratégias direcionadas a mercados estrangeiros. Pois, ao final, a exibição de novas entradas no mercado internacional, como é necessário para

\section{Organizadores:}

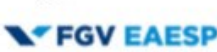

\section{commo or}

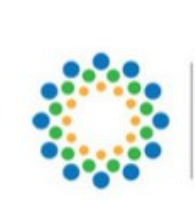

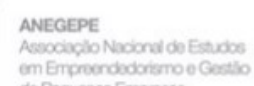

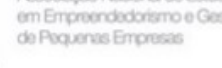

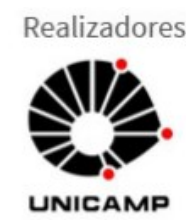


reivindicar a manifestação da OEI, é um resultado organizacional, não uma característica pessoal (KUIVALAINEN; SUNDQVIST; SERVAIS, 2007).

A pesquisa analisou e descreveu medidas que caracterizam dimensões, categorias e elementos de OEI como parte da estratégia de quatro empresas do aerodesporto, empresas exportadoras, influenciadas por dinâmicas de mercados, normatizações e certificações estrangeiras. Colaboram para a compreensão de como são aplicadas estratégias de marketing internacional competitivas e agressivas, para conquistar mercados internacionais (KNIGHT; CAVUSGIL, 1996). No entanto, esta pesquisa adota o conceito de distância de mercado (COVIELLO; JONES, 2004), definido como diversidade entre mercados, por ser um indicador correspondente à intensidade das atividades de internacionalização realizadas pelas empresas (KUIVALAINEN et al., 2007). Há o entendimento de que o movimento de internacionalização cria paradigmas de gestão, que se apresentam na forma de agressividade competitiva e autonomia na busca por oportunidades internacionais.

Ainda que em termos de diversidade de mercados, reconhece-se que novas entradas no sentido da OEI implicam em entradas em novos mercados internacionais, diferentemente da forma como são avaliadas pelo constructo de $\mathrm{OE}$, que entende novas entradas como sendo a apresentação de novos produtos internacionalmente. Nessa ótica, o objetivo geral desse estudo, consiste em verificar empiricamente se as dimensões da OEI - inovatividade, proatividade e assunção de riscos, agressividade competitiva e autonomia - se aplicam e se relacionam às organizações exportadoras brasileiras fabricantes de produtos para 0 aerodesporto, todas caracterizadas como international new venture (INV).

O estudo está dividido em seções: (i) breve introdução considerando tema e o objetivo; (ii) referencial teórico consolidado; (iii) metodologia; (iv) os resultados da pesquisa empírica, e (v) discussão e implicações práticas, reconhecendo devidamente as limitações do estudo.

\section{Referencial Teórico}

Após o levantamento das principais ideias existentes sobre negócios internacionais que envolvem os temas de Internacionalização de Empresas, EI e OE, a revisão da literatura apoiou-se em Flick (2002), buscando entender um tema em processo de consolidação e criar uma pesquisa qualitativa com o propósito de operacionalizar um referencial teórico atualizado. A pesquisa valeu-se dos princípios de codificação temática, com emprego do software de apoio a pesquisas qualitativas, o NVIVO (LAGE; GODOY, 2008; LAGE, 2011). A fase da busca e seleção inicial usou bases de dados eletrônicas, como as bibliotecas da CAPES-Periódicos, Ebsco-host, Elsevier Science Direct e Proquest e periódicos classificados no extrato A1 do Qualis/Capes, a exemplo do jornal Entrepreneurship: Theory and Practice.

\subsection{Internacionalização de Empresas}

O desenvolvimento de uma abordagem comportamental sobre internacionalização de empresas é observado a partir de meados da década de 1970, como decorrência do pensamento desenvolvido pela Escola de Uppsala, sob a perspectiva da teoria do 
comportamento organizacional (BARRETO; NASSIF, 2014); Adicionalmente à perspectiva de resource based view que estuda os processos de internacionalização pelo conceito de capacidades dinâmicas como elemento central na análise, argumenta se que as empresas mais bem-sucedidas conseguem renovar continuamente seus recursos e capacidades, em pontos fortes cumulativos como foco estratégico (SAPIENZA; AUTIO; GEORGE; ZAHRA, 2006).

Tal abordagem, suscita uma concepção capaz de integrar as teorias econômica e comportamental, usadas para explicar o processo de internacionalização de empresas. Assim, as possíveis implicações para o constructo de OEI são que recursos como relacionamentos, sejam eles, conexões internacionais, alianças exclusivas com distribuidores, licenças e certificações estrangeiras e outros ativos, constituem vantagens competitivas que facilitam processos de internacionalização como meio de entradas efetivos, que demandam esforços da organização, e por sua vez evidenciam mais claramente os elementos do EI que resultam em novas oportunidades, como ações que diferenciam as empresas em termos de adaptação, execução e capacidade de gestão (SILVA; MORAES, 2013; LEITE; MORAES; SALAZAR, 2015).

Considerando o número de mercados e diversificação alcançada por algumas empresas, fundamenta-se o estudo na teoria de internacionalização de empresas com o propósito de compreender quando novos produtos, serviços, mercados e métodos organizacionais (LUMPKIN; DESS, 1996), podem ser exemplificados como atividades ou resultados das empresas ao refletirem a intensidade das dimensões da OE na busca por mercados internacionais (KNIGHT; CAVUSGIL, 2004). Entende-se que tais ações se destinam a ampliar o escopo internacional, e incrementar a experiência gerencial e operacional da empresa (SCHWEIZER; VAHLNE; JOHANSON, 2010). Para tanto, a internacionalização seria um atributo para identificar a situação em que se encontra o processo de expansão internacional em termos de crescimento e criação de valor, quando determinantes organizacionais associados ao tamanho da firma, vendas, número de parceiros e experiência internacional influenciam este mesmo processo, à medida que as atividades internacionais vão se expandindo geograficamente (HONORIO, 2009).

Desde uma visão organizacional, Johanson e Vahlne (1977;1990) explicam a internacionalização de empresas pela perspectiva do empreendedor, considerando a experiência e comportamentos dos indivíduos e a influência das redes de relacionamentos. Em Pequenas e Medias Empresas (PME), tal abordagem do papel central do empreendedor na literatura de internacionalização tem se estabelecido pelos caminhos da investigação sobre as competências necessárias para uma experiência internacional bem-sucedida, segundo autores como Etemad (2004), Ruzzier, Hisrich e Antoncic (2006) e Schweizer, Vahlne e Johanson (2010). Em sentido semelhante, Wiklund (1998) afirma que assim como o comportamento empreendedor em nível individual pode afetar a ação organizacional, em muitos casos os comportamentos empreendedores, individual e organizacional, podem ser muito semelhantes,

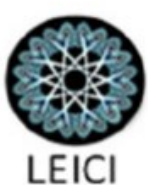


como é o caso de PMEs envolvidas com processos de internacionalização (MATLAY et al., 2006; SLEVIN; TERJESEN, 2011).

Sobre International New Venture (INV), autores como Dib, Rocha e Silva (2010) discutiram os aspectos teóricos do fenômeno born global (BG) e concluíram que a literatura da área de negócios internacionais apresenta certa dificuldade para explicar a distinção entre novas empresas internacionais em relação às capacidades empreendedoras e à velocidade dos processos de internacionalização. Nota-se que estudos de Cavusgil e Knight (2015) forneceram alguma compreensão inicial destes tipos de padrões de internacionalização de empresas e, mais especificamente, sugeriram que estratégias de mercado estrangeiro podem ser formuladas de várias maneiras, ou seja, alguns planejados e outros por meios da experiência e aprendizado originais, mas que BG e INV exibem características diferentes.

Segundo a revisão da literatura sobre INV feita por Aspelund, Madsen e Moen (2007), os autores mencionam OEI como sendo um fator decisivo para o estabelecimento de BG, pois dentro do EI os gestores, fundadores ou a equipe de gestão de INV são assumidos como portadores de conhecimento, capacidades e preferências particulares refletidas nos graus de intensidade da OEI, resultando em novas entradas internacionais (KEUPP; GASSMANN, 2009).

As características dos processos de internacionalização aplicadas neste estudo foram organizadas na forma de quadro, com a finalidade de fornecerem uma visualização mais clara sobre INV e suas diferenças nos casos abordados, exemplificando assim possíveis diferenças entre as empresas da indústria de produtos para o aerodesporto, segue o Quadro 1 abaixo:

Quadro 1: Diferenças entre processos de internacionalização

\begin{tabular}{|c|c|c|}
\hline Elementos & Modelo de Uppsala & Teoria Born Global \\
\hline Características das empresas & $\begin{array}{l}\text { firmas estabelecidas e } \\
\text { grandes }\end{array}$ & $\begin{array}{lcc}\text { empresas } & \text { jovens, pequenas, com } \\
\text { estruturas } & \text { híbridas e recursos } \\
\text { limitados } & & \end{array}$ \\
\hline Estratégia de negócios & $\begin{array}{l}\text { sem referência a custos e } \\
\text { diferenciações }\end{array}$ & $\begin{array}{l}\text { oferecer produtos inovadores com } \\
\text { alta qualidade, controle de custos em } \\
\text { mercados de nicho }\end{array}$ \\
\hline Abordagem de internacionalização & reativo e oportunista & proativo e planejado \\
\hline Velocidade da internacionalização & devagar e incremental & rápida e precoce \\
\hline Mercado doméstico & mercado robusto & sem importância \\
\hline Distancia psíquica & abrangência limitada & $\begin{array}{l}\text { não é restrição para a } \\
\text { internacionalização }\end{array}$ \\
\hline Razões para internacionalizar & $\begin{array}{l}\text { diversificar riscos e buscar } \\
\text { solidez mercadológica }\end{array}$ & $\begin{array}{l}\text { buscar crescimento e exploração de } \\
\text { oportunidades internacionais para } \\
\text { aumentar participação de mercado e } \\
\text { lucros }\end{array}$ \\
\hline Vantagem mercadológica & vários anos de operação & $\begin{array}{l}\text { forte competência em tecnologias e } \\
\text { conhecimentos específicos }\end{array}$ \\
\hline Visão de mercados internacionais & mercados vistos como risco & mercados vistos como oportunidade \\
\hline
\end{tabular}




\begin{tabular}{|l|l|l|} 
Experiência e conhecimento internacional & $\begin{array}{l}\text { conhecimento adquirido } \\
\text { somente após a experiência } \\
\text { de internacionalização }\end{array}$ & $\begin{array}{l}\text { empreendedor é peça chave por exibir } \\
\text { experiência e conhecimentos de } \\
\text { mercados estrangeiros }\end{array}$ \\
\hline Decisões de compromisso de mercado & $\begin{array}{l}\text { compromisso gradual } \\
\text { devido às incertezas }\end{array}$ & $\begin{array}{l}\text { empreendedor possui conhecimentos } \\
\text { de mercados e agiliza compromissos }\end{array}$ \\
\hline Redes de relacionamento & $\begin{array}{l}\text { redes gradualmente } \\
\text { substituídas por recursos } \\
\text { próprios }\end{array}$ & $\begin{array}{l}\text { redes são cruciais para expansão, } \\
\text { criação e posicionamentos }\end{array}$ \\
\hline
\end{tabular}

Fonte: adaptado de Aspelund, Madsen e Moen (2007)

\subsection{Empreendedorismo Internacional}

Para evoluir a pesquisa para EI, visou-se aplicar uma nova abordagem, a fim de entender como os novos empreendimentos internacionais desenvolvem vantagem competitiva devido a vendas em diversos países (OVIATT; MCDOUGALL,1994). Diferentemente do processo incremental sugerido pelo Modelo de Uppsala, algumas empresas para se manterem competitivas, buscam no exterior não apenas mercados potenciais, mas também fontes de mão de obra, conhecimentos e matérias primas (ROWDEN,2001). Por uma perspectiva de EI, vale notar que os empreendedores internacionais enfrentam diversas decisões ligadas às redes internacionais da empresa, sendo que a utilização das estratégias e atitudes mais adequadas pode significar a diferença entre crescimento rápido ou lento, devido a um desafio duplo, segundo Autio, Sapienza e Arhenius (2000): a superação das dificuldades de ser uma empresa iniciante e de ser uma empresa estrangeira num mercado internacional, com concorrência global.

Segundo Peiris, Akoorie e Sinha (2012), os estudos na área de EI apareceram por volta de 1990 como uma resposta à natureza dinâmica das INV's, percebidas como anomalias ao padrão de internacionalização de empresas, todavia deriva dos autores McDougall e Oviatt (2000, p. 903) a definição da área de pesquisa: "uma combinação de inovação, proatividade e assunção de risco como comportamento, que atravessa as fronteiras nacionais com a intenção de criar valor nas organizações". Nota-se que pesquisadores do domínio do EI consideram que empreendedorismo e internacionalização estão relacionados a modos de entradas e exploração de mercados internacionais (LUMPKIN; DESS, 1996), como um processo de construção de posicionamento em uma rede de clientes e fornecedores pertencente a mercados estrangeiros (MCDOUGALL; OVIATT, 2000).

Leite e Moraes (2014) oferecem uma ampla visualização dos temas estudados em EI, dentro do pensamento brasileiro. Percebe-se na literatura nacional, um forte interesse por assuntos de adaptação à competição internacional, dado que o contexto do EI é majoritariamente abordado por tópicos de cultura organizacional, capacidade de gestão e centralização das decisões pelo empreendedor (LEITE; MORAES, 2014). Para Coviello (2015), EI está diretamente ligado ao aspecto dos resultados alcançados pelas ações dos empreendedores, o que corrobora com a importância da pesquisa sobre o empreendedor,

\section{Organizadores:}

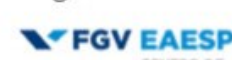

\section{commo or}
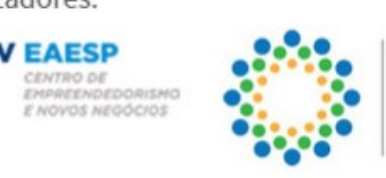

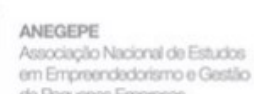

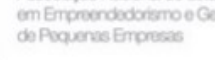
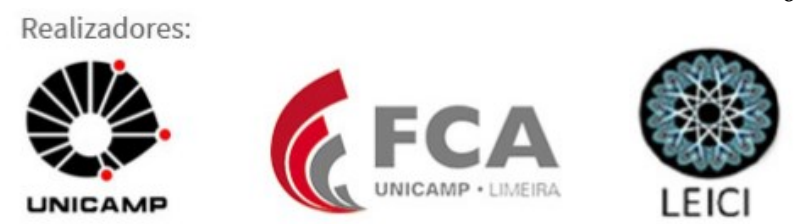
como apontada por Cavusgil e Knight (2015) ao reiterar as proposições de Jones e Coviello (2005), com o argumento de que a atitude e as intensões do empreendedor merecem atenção. Da mesma forma, chamados por mais estudos sobre o empreendedor foram feitos por autores como Autio (2005) e Zahra (2005) por meio de comentários sobre o artigo de Oviatt e McDougall (1994), explicando a formação de INV.

Ao observar o comportamento do empreendedor como manifestações das características mantidas por este durante a condução do processo empreendedor. Considera-se o indivíduo como função empreendedora dentro da empresa, pois acredita-se que a motivação para se internacionalizar está em estreita relação com o processo de formação e escolha das estratégias que a organização estabelece, para reconhecer e explorar as oportunidades oferecidas pelo mercado internacional (SHANE; VENKATARAMAN, 2000; DIMITRATOS; PLAKOYIANNAKI, 2003; ZAHRA et al., 2004).

\subsection{Orientação Empreendedora Internacional}

Para Wales (2016) a Orientação Empreendedora tornou-se um conceito estabelecido na pesquisa sobre empreendedorismo, porque descreve quando uma organização se apresenta como mais empreendedora que outra, quando demonstra um padrão sustentado de comportamento por certo tempo, geralmente caracterizado por inovação, proatividade e assunção de risco, manifestados em seu comportamento estratégico (MARTENS et al., 2016).

Segundo Martens e Freitas (2007), empreendedorismo no nível da organização se refere à $\mathrm{OE}$ como métodos, práticas e estilos de tomada de decisão gerencial usados pela organização para agir de forma empreendedora. Conforme os autores, ela emerge de uma perspectiva de escolha estratégica, a qual afirma que oportunidades de crescimento podem ser empreendidas com sucesso de forma deliberada, assim apresentados por Covin e Slevin (1989), Zahra e Covin (1995).

Para dar sentido à discussão a respeito da evolução do tema para OEI, do mesmo jeito que Miller (1983) e Wiklund (1998) discutiram que o empreendedorismo é integralmente associado a variáveis de ambiente, estrutura, estratégia e personalidade do líder, percebe-se pelas observações feitas nos estudos desses autores, que em matéria de PME, o empreendedorismo é predominantemente influenciado pela liderança, personalidade, força e informação do líder ou da liderança.

Do ponto de vista operacional, Miller (1983) apresentou três dimensões da OE: (i) inovatividade, como a busca por soluções criativas para novas tecnologias, processos, materiais, produtos e serviços; (ii) proatividade, para antecipar as mudanças no mercado e explorar as oportunidades identificadas; (iii) assunção de riscos, necessária para utilização racional dos recursos com as oportunidades identificadas. Lumpkin e Dess (1996), ao considerarem que as dimensões poderiam variar de intensidade nas empresas independentemente do contexto, completaram com mais duas dimensões: (iv) autonomia,

\section{Organizadores:}

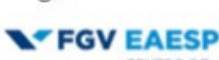

\section{commo or}

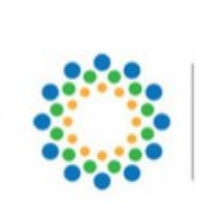

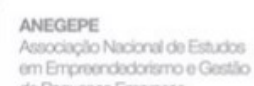

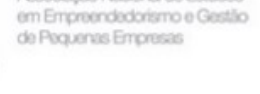
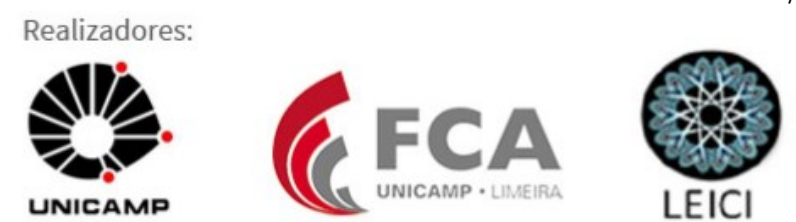
como a habilidade de independentemente desenvolver, produzir e implementar novas ideias; e (v) agressividade competitiva, focado em competidores e não em mercados.

Avançando nessa perspectiva, aproveita-se o que Knight (2001), Zhara e George (2002), Knight e Cavusgil (2004), Covin e Wales (2011), Slevin e Terjesen (2011) e Covin e Miller (2014) apresentam em seus estudos, no entanto, esta pesquisa corrobora com a visão de desprender esforços para investigar se atribuição de uma OEI para empreendedores internacionais pode simplesmente ocorrer porque esses indivíduos fundaram empresas que se envolveram em novas entradas internacionais, ou seja, a presença da ação de entrada em novos mercados tomada como prova de que o empreendedor internacional possui OEI.

\section{Metodologia}

Por tratar-se de análise qualitativa por meio de um estudo de caso múltiplo (GODOY, 1995; YIN, 2005; MARTINS, 2008), foi adotada a tipologia de Gil (1991) para classificar a pesquisa como exploratória e também do tipo descritiva, pois destinou-se prioritariamente a delinear as percepções de pessoas quanto aos fatores que influenciam o desenvolvimento de competências gerenciais (GIL; LICHT; OLIVA, 2005; MOZZATO; GRZYBOVSKI; TEIXEIRA, 2016). Todavia, segundo Mozzato e Grzybovski (2011), embora não exista um procedimento padronizado na condução de análises qualitativas com o auxílio de softwares, utilizar programas tipo CAQDAS vem sendo cada vez mais comum no campo da administração, constituindo meio válido de análise de dados qualitativos, transcrição de textos, codificação e interpretação de textos. Por exemplo, a classificação por meio da matriz de codificação no NVIVO possibilita análises e explorações das codificações de forma cruzada, permitindo comparações entre o material codificado e os temas específicos da pesquisa, ocupando-se das duas estratégias gerais de análise desse artigo, tanto com o uso de fontes teóricas como com a descrição de casos (YIN, 2005).

Devido a sua complexidade de avaliação, no Quadro 2 apresenta-se uma matriz de amarração para facilitar a compreensão do estudo qualitativo sugerido e suas fases correspondentes (TELLES, 2001).

\section{Quadro 2 - Matriz de amarração da pesquisa desenvolvida.}

\begin{tabular}{|c|c|c|c|}
\hline Modelo de Pesquisa & Modelo Teórico & Modelo operacional & Análise dos Dados \\
\hline $\begin{array}{l}\text { Identificação de bases de } \\
\text { dados para OEI }\end{array}$ & $\begin{array}{l}\text { Construção de base de } \\
\text { dados sobre } \\
\text { Internacionalização de } \\
\text { empresas, EI e OE }\end{array}$ & $\begin{array}{lr}\text { Utilização } & \text { de } \\
\text { programas } & \text { tipo } \\
\text { CAQDAS } & \text { para } \\
\text { sínteses e análises de } \\
\text { conteúdo }\end{array}$ & \multirow{2}{*}{$\begin{array}{l}\text { 1. Pesquisa Qualitativa (Análise } \\
\text { temática, documental e entrevistas } \\
\text { em profundidade); 2. Análise de } \\
\text { conteúdo (identificação de } \\
\text { similaridades e diferenças entre as } \\
\text { organizações) }\end{array}$} \\
\hline $\begin{array}{l}\text { Compreensão da estrutura } \\
\text { de OEI em termos de } \\
\text { dimensões e categorias }\end{array}$ & $\begin{array}{l}\text { Reconhecimento de } \\
\text { conteúdo e forma da OEI } \\
\text { praticada em termos de } \\
\text { autores e artigos } \\
\text { disponíveis na literatura }\end{array}$ & $\begin{array}{l}\text { Entendimento de } \\
\text { procedimentos, } \\
\text { formato e apresentação } \\
\text { do conteúdo de OEI }\end{array}$ & \\
\hline
\end{tabular}




\begin{tabular}{|c|c|c|c|}
\hline $\begin{array}{l}\text { Levantamento dos } \\
\text { elementos considerados } \\
\text { como Práticas gerenciais }\end{array}$ & $\begin{array}{l}\text { Revisão da literatura e } \\
\text { situação temporal das } \\
\text { teorias aplicadas }\end{array}$ & \begin{tabular}{|lr} 
Codificação & das \\
variáveis & relevantes \\
utilizadas & na \\
elaboração & do \\
constructo aplicado & \\
\end{tabular} & $\begin{array}{l}\text { 1. Pesquisa qualitativa (entrevistas } \\
\text { semiestruturadas); } 2 \text {. Caracterização } \\
\text { das empresas; } 3 \text {. Levantamento das } \\
\text { atividades por dimensões e } \\
\text { elementos de OEI }\end{array}$ \\
\hline $\begin{array}{l}\text { Avaliação das atividades } \\
\text { internacionais } \\
\text { empresas }\end{array}$ & $\begin{array}{|lr|}\text { Exploração } & \text { das } \\
\text { condições } & \mathrm{e} \\
\text { possibilidades } & \mathrm{de} \\
\text { avaliação dos } & \text { atuais } \\
\text { modelos } & \\
\end{array}$ & $\begin{array}{l}\text { Sistematização e uso } \\
\text { de ferramentas de } \\
\text { suporte e avaliação das } \\
\text { entregas e resultados }\end{array}$ & $\begin{array}{l}\text { Análise de conteúdo das entrevistas } \\
\text { em profundidade }\end{array}$ \\
\hline $\begin{array}{l}\text { Elaboração do estudo de } \\
\text { caso múltiplo }\end{array}$ & $\begin{array}{l}\text { Seleção do modelo } \\
\text { conceitual aplicado }\end{array}$ & $\begin{array}{l}\text { Definição do modelo } \\
\text { de referência para a } \\
\text { elaboração e validação } \\
\text { do estudo }\end{array}$ & $\begin{array}{l}\text { Análise do estudo de caso múltiplo } \\
\text { (triangulação, } \\
\text { sistemática) }\end{array}$ \\
\hline
\end{tabular}

Fonte: adaptado de Telles (2001)

Após o levantamento conceitual, desenvolveu-se um modelo de pesquisa final motivado pelos trabalhos de Freitas et al., (2012) para as análises sobre OEI, e nos artigos de Dib, Da Rocha, Da Silva, (2010) para caracterizar empiricamente o fenômeno INV nas empresas de aerodesporto. Para prosseguir com a coleta de dados, após o aceite dos empresários, foram então agendadas as entrevistas presenciais. Utilizou-se como instrumento um roteiro semiestruturado desenvolvido à luz das práticas gerenciais, adaptado às empresas do aerodesporto no Quadro 3 abaixo:

\section{Quadro 3: Elementos e Práticas Gerenciais}

\begin{tabular}{|c|c|c|}
\hline \multirow{2}{*}{ Dimensões da OEI } & \multicolumn{2}{|r|}{ Elementos Gerenciais } \\
\hline & Categorias & Praticas Gerenciais \\
\hline \multirow{5}{*}{ 爰 } & Produtos para o mercado externo & $\begin{array}{c}\text { \# DE NOVOS PRODUTOS \# LINHAS \# DE MUDANÇAS PARA ATENDER } \\
\text { INTERNACIONALMENTE E A FREQUENCIA DE MUDANÇA POR CAUSA DO MERCADO } \\
\text { EXTERIOR }\end{array}$ \\
\hline & $\begin{array}{l}\text { Inovação em processos para atuar no } \\
\text { mercado exterior }\end{array}$ & $\begin{array}{l}\text { ADAPTAÇÃO EM PROCESSOS ADMINISTRATIVOS, TECNOLOGICOS, EM PRODUTO E } \\
\text { MERCADOS -ALVOS }\end{array}$ \\
\hline & Recursos Financeiros & $\begin{array}{c}\text { RECURSOS FINANCEIROS INVESTIDOS EM INOVAÇÃO MESMO EM TEMPOS DE } \\
\text { DIFICULDADES ECONOMICAS }\end{array}$ \\
\hline & $\begin{array}{l}\text { Criatividade para atuar } \\
\text { internacionalmente }\end{array}$ & ENGAJAMENTO E TESTES, EXPERIMENTOS EM RELAÇÃO AO MERCADO EXTERNO \\
\hline & Diferenciação pelo mercado externo & INICIATIVAS DE DIFICIL IMITAÇÃO PELO COMPETIDORES INTERNACIONAIS \\
\hline \multirow{4}{*}{ 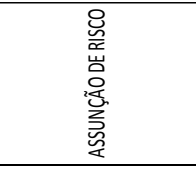 } & Risco geral & FORTE TENDENCIA A PROJETOS DE ALTO RISCO PARA ATENDER O MERCADO EXTERIOR \\
\hline & Risco de decisão & $\begin{array}{c}\text { PREFERENCIA DOS GESTORES POR AGIR COM AUTONOMIA E ASSUNÇAO DE RISCO } \\
\text { PESSOAL PARA EXPLORAR O MERCADO EXTERIOR }\end{array}$ \\
\hline & Risco financeiro & RISCO DE PERDA FINANCEIRA OU SEM PREMIO \\
\hline & Risco de negócios & AÇÕES DE GRANDE PORTE DEVIDO A HOSTILIDADE DO AMBIENTE \\
\hline \multirow{4}{*}{ 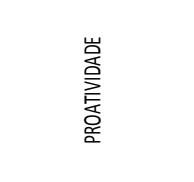 } & Monitoramento & MONITORAMENTO E PESQUISA DO MERCADO EXTERIOR \\
\hline & Antecipação & PIONEIRISMO E TENDENCIA DE ATAQUE AO MERCADO EXTERIOR \\
\hline & Resolução de problemas & $\begin{array}{l}\text { PARTICIPAÇÃO E CONTROLE COMO PLANEJAMENTO PARA SOLUÇÃO DE PROBLEMAS E } \\
\text { OPORTUNIDADES }\end{array}$ \\
\hline & Adaptação e flexibilidade & $\begin{array}{l}\text { DISPONIBILIDADE E ACESSO DE PESSOAS, RECURSOS E EQUIPAMENTOS NECESSARIOS } \\
\text { PARA TER HABILIDADES DE FLEXIBILIDADE PARA ATENDER NECESSIDADES DO } \\
\text { MERCADO EXTERIOR }\end{array}$ \\
\hline \multirow{4}{*}{ 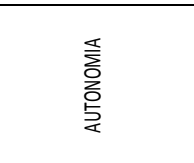 } & Equipe & $\begin{array}{c}\text { LIDERES COM COMPORTAMENTO AUTONOMO QUE COORDENAM ATIVIDADES COM } \\
\text { MEDIDAS E MONITORAMENTO INTERNACIONAL }\end{array}$ \\
\hline & Centralização & MODELO DE GESTÃO, DECISÃO E DELEGAÇÃO DE AUTORIDADE \\
\hline & Responsabilização & $\begin{array}{l}\text { PARTICIPAÇÃO EM PROJETOS SETORIAIS, CONSORCIADOS OU INDEPENDENTES PARA } \\
\text { FOMENTO DAS AÇÕES DE PROSPECÇÃO DE MERCADO EXTERNO }\end{array}$ \\
\hline & Capacidade organizacional & $\begin{array}{l}\text { AÇÃO DEPARTAMENTAL OU UNIDADES DE NEGOCIOS COORDENADOS POR GESTORES } \\
\text { COM CARACTERISTICAS EMPREEDENDORAS }\end{array}$ \\
\hline \multirow{4}{*}{ 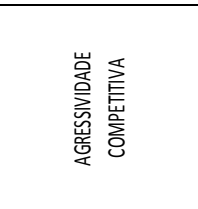 } & Reação a competição & $\begin{array}{l}\text { MOVIMENTAR EM REAÇÃOO OU COM PROTAGONISMO AGRESSIVO EM RELAÇÃO AOS } \\
\text { COMPETIDORES E MUDANÇAS NO MERCADO EXTERIOR }\end{array}$ \\
\hline & Competição financeira & BUSCA DE POSICIONAMENTO A CUSTAS DE FLUXO DE CAIXA, RENTABILIDADE \\
\hline & Competição de negócios & $\begin{array}{l}\text { AGRESSIVIDADE PARA CONFRONTAR TENDENCIAS DE MUDANÇAS DESFAVORAVEIS. } \\
\text { IMITAÇÃO E COPIA OU USO DE METODOS DE COMPETIÇÃO NÃO CONVENCIONAIS }\end{array}$ \\
\hline & Posicionamento de mercado & $\begin{array}{l}\text { MARKETING INTERNACIONAL MIX PARA NOVOS PRODUTOS, SERVIÇOS, DISTRIBUIÇÃO } \\
\text { E MERCADOS DIFERENTES }\end{array}$ \\
\hline
\end{tabular}




\section{Resultados}

De uma maneira geral, McDougall, Shane e Oviatt (1994) colocam que o processo de formação das BG não é explicado pelas teorias existentes no campo dos negócios internacionais, enquanto algumas abordagens permitem o entendimento do que seja uma INV. Conforme Dib, Rocha e Silva (2010), as primeiras definições operacionais importantes na pesquisa de INV dizem respeito ao universo em que estão inseridas as empresas, dependendo de como se pretende analisar as estratégias de internacionalização correspondentes. Uma estratégia de internacionalização de empresas, para ser definida em termos de escala e escopo, tem na medida tempo o elemento que diferencia os estudos que enfocam BG dos estudos centrados nos processos de internacionalização de pequenas e médias empresas tradicionais (KUIVALAINEN et al., 2007).

No Quadro 4 a seguir, estão apresentados relatos sobre as principais características definidoras do que seria uma empresa INV/BG entre as empresas amostradas no setor de aerodesporto. Considerando o quadro, duas características importantes, a data de estabelecimento da empresa e o início das atividades internacionais, dão as diferenças de velocidades de desenvolvimento encontrados nos casos estudados (JONES; COVIELLO, 2005).

Nas pesquisas sobre internacionalização precoce e rápida, percebe-se a diferença em termos de data de estabelecimento. Entretanto, a literatura varia desde autores como Rasmussen, Madsen e Evangelista (2001), que consideram empresas estabelecidas após 1976, Autio e Sapienza (2000) que estudaram empresas estabelecidas após 1986 e inclusive fica evidente o ano de 1990, citado por vários estudos como sendo a data a partir da qual a literatura deveria considerar o fenômeno INV (DIB; ROCHA; SILVA, 2010).

Todavia, com a intenção de facilitar o entendimento do resultado geral, no Quadro 5, segue com uma ilustração das categorias estudadas, considerando-se as dimensões da OEI apresentadas em coloração azul, conforme a intensidade com que elas repercutem nas organizações (FREITAS et al., 2012). 
Quadro 4: Características INV/BG das empresas do aerodesporto

\begin{tabular}{|c|c|c|c|c|}
\hline CARACTERISTICAS & SOL PARAGLIDERS & ROTOR HARNESS & TIRANTE A & TRIKE ICAROS \\
\hline ABRANGENCIA GEOGRAFICA & \begin{tabular}{|c|}
56 Distribuidores - \\
Exportações: Africa do Sul, \\
Alemanha, Argentina, \\
Australia, Austria, Belgica, \\
Bolivia, Canada, Chile, \\
Colombia, Costa Rica, \\
Dinamarca, Equador, \\
Espanha, EUA, Finlandia, \\
Formosa, França, Guatemala, \\
Hong kong, India, Islandia, \\
Israel, Italia, Japão, \\
Macedonia, Malasia, \\
Martinica, Mexico, \\
Montenegro, Nova Zelandia, \\
Panama, Paquistão, Peru, \\
Porto Rico, Portugal, Reino
\end{tabular} & $\begin{array}{c}10 \text { Distribuidores - } \\
\text { Exportações: Alemanha, } \\
\text { Canada; Estados Unidos, } \\
\text { Italia, Japão, Mexico, } \\
\text { Noruega, Reino Unido, Rep. } \\
\text { Checa, Russia. }\end{array}$ & \begin{tabular}{|c|}
15 Distribuidores - \\
Exportações: Alemanha, Costa \\
Rica, Emirados Arabes Unidos, \\
Espanha, Estados Unidos, \\
França, Italia, Irlanda, Iraque, \\
Hungria, Rep. Da Coréia do \\
Sul, Russia, Suiça, Turquia, \\
Venezuela.
\end{tabular} & $\begin{array}{c}\text { Exportações - Argentina, } \\
\text { Estados Unidos, Italia, Peru, } \\
\text { Uruguai }\end{array}$ \\
\hline CONCENTRAÇÃO & \begin{tabular}{|c|} 
"A Sol Paragliders é uma \\
empresa de aviação aérea \\
desportiva, voltada ao lazer \\
aéreo, ao esporte, e atividade \\
paraglider"
\end{tabular} & $\begin{array}{c}\text { "A Rotor Equipamentos } \\
\text { fabrica produtos de voo livre } \\
\text { para asa delta" }\end{array}$ & $\begin{array}{c}\text { "Uma empresa de serviço, } \\
\text { onde a gente desenvolvia } \\
\text { projetos eletrônicos pra } \\
\text { terceiros" }\end{array}$ & $\begin{array}{c}\text { "Na realidade agora, nós } \\
\text { estamos como aeronaves } \\
\text { leves esportivas e aeronaves } \\
\text { aerodesportivas" } \\
\text { " }\end{array}$ \\
\hline \begin{tabular}{|l|} 
DATA DE ESTABELECIMENTO \\
\end{tabular} & 1991 & 1983 & 2009 & 1986 \\
\hline ESCOPO DAS ATIVIDADES & \begin{tabular}{|c|} 
"Pela $18^{a}$ vez consecutiva a \\
SOL Paragliders se fez \\
presente no maior evento de \\
voo livre do Mundo A feira de \\
Saint Hilaire e Copa Icare \\
França. Desde que a empresa \\
decidiu pela sua \\
internacionalização, \\
desenvolvimento e pesquisa \\
próprios, a empresa expõem e \\
participa deste tradicional \\
evento que neste ano realizou \\
a sua 44a Edição" \\
\end{tabular} & \begin{tabular}{|} 
"Os meus melhores \\
representantes são aqueles \\
que no pós-venda, os caras \\
fazem até manutenção de \\
costura, os caras tem a \\
máquina de costura, se \\
precisar trocar um zíper, uma \\
peça..."
\end{tabular} & $\begin{array}{l}\text { "Um distribuidor em cada país } \\
\text { que a gente visita, né?! Mas, } \\
\text { é, de modo geral, era um } \\
\text { distribuidor por país e esse } \\
\text { cara tinha a estratégia dele" }\end{array}$ & $\begin{array}{l}\text { "Por exemplo, na Argentina } \\
\text { colocamos um representante, } \\
\text { que ele abriu um site nosso" }\end{array}$ \\
\hline INICIO DAS ATIVIDADES & 1993 & 1998 & 2010 & 2003 \\
\hline MODO DE ENTRADA & $\begin{array}{c}\text { Representação - } \\
\text { Licenciamento - IMP/EXP } \\
\text { Direta - Distribuidoress }\end{array}$ & \begin{tabular}{|c|} 
"A partir desse campeonato \\
na Itália, em 1998, eu comecei \\
a ter representantes "
\end{tabular} & $\begin{array}{l}\text { "Como dealers, né, essa } \\
\text { estratégia a gente entende } \\
\text { que é muito inteligente, }\end{array}$ & $\begin{array}{c}\text { Representação - IMP/EXP } \\
\text { Direta }\end{array}$ \\
\hline MOTIVAÇÕES & $\begin{array}{c}\text { "É, porque depois, quando } \\
\text { comecei a fazer a gente já viu } \\
\text { as dificuldades de se manter } \\
\text { atualizado, não é? Porque lá a } \\
\text { cada seis meses havia um } \\
\text { parapente que estava em } \\
\text { evidência, a cada quatro } \\
\text { meses, não é?" }\end{array}$ & $\begin{array}{l}\text { "O externo que ajudou a } \\
\text { trabalhar o mercado interno. } \\
\text { Daí a inovações foram o que } \\
\text { abriram mais mercados" }\end{array}$ & \begin{tabular}{|} 
"o fato da gente tá na feira, da \\
gente expor lá, de começar a \\
vender na Europa, né?! \\
Trouxe alguns outros caras, \\
né?! É, então, a gente \\
apareceu na Thermik, que é \\
uma revista alemã, né?! \\
Aparecemos na Parapente \\
Plus que é uma revista \\
francesa, né?! Fizeram \\
reportagem e tal. Então isso \\
gerou também leads, né, \\
contatos do pessoal de fora"
\end{tabular} & $\begin{array}{l}\text { Como lá não tem fabricante, o } \\
\text { mais próximo seríamos nós. } \\
\text { Então ele quis ele... Ele na } \\
\text { verdade que nos procurou } \\
\text { para nos representar" }\end{array}$ \\
\hline PORTE & $\begin{array}{c}\text { "até 2000, a gente tinha } \\
\text { vinte funcionários, para ter } \\
\text { uma ideia, não é? E aí em } \\
2010 \text { a gente estava com } 150\end{array}$ & $\begin{array}{c}\text { "Eu trabalhava sozinho. } \\
\text { Trabalhava a minha ex-mulher } \\
\text { comigo, não na parte de } \\
\text { produção, ela trabalhava na }\end{array}$ & 5 pessoas & 5 pessoas \\
\hline RELEVANCIA DAS ATIVIDADES & $\begin{array}{c}\text { "mesmo } 50 \% \text { seja enviado a } \\
\text { mercados internacionais, a } \\
\text { exportação representa } \\
\text { somente } 30 \% \text { do faturamento } \\
\text { anual" }\end{array}$ & $\begin{array}{l}\text { "alem de vender, a gente é } \\
\text { competidor, então a gente } \\
\text { está sempre em } \\
\text { desenvolvimento no fato de } \\
\text { estar em contato com os } \\
\text { pilotos top do mundo" }\end{array}$ & $\begin{array}{c}\text { "Hoje nós não estamos } \\
\text { exportando mais. Mas chegou } \\
\text { a ser coisa de } 15 \% \text { das nossas } \\
\text { vendas" }\end{array}$ & $\begin{array}{l}\text { "depois que eu criei a página } \\
\text { no Facebook a gente } \\
\text { conseguiu uma proximidade } \\
\text { maior com o mercado, tanto } \\
\text { com o mercado nacional, } \\
\text { quanto com o internacional. }\end{array}$ \\
\hline
\end{tabular}


Quadro 5: ilustração das dimensões e categoria de OEI conforme intensidades exibidas nas empresas do aerodesporto.

\begin{tabular}{|c|c|c|c|c|c|}
\hline DIMENSÕES & CATEGORIAS & SOL PARAGLIDERS & ROTOR HARNESSES & TIRANTE A & TRIKE ICAROS \\
\hline \multirow{4}{*}{$\begin{array}{l}\sum \\
\sum \\
0 \\
0 \\
0 \\
\frac{1}{2}\end{array}$} & Ação Independente & & & & \\
\hline & Centralizacao & & & & \\
\hline & Equipe Internacional & & & & \\
\hline & Intraempreendedorismo & & & & \\
\hline \multirow{4}{*}{ 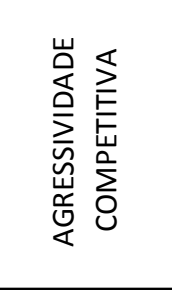 } & $\begin{array}{l}\text { Competição em Negocios } \\
\text { Internacionais }\end{array}$ & & & & \\
\hline & Competição financeira & & & & \\
\hline & Marketing Internacional & & & & \\
\hline & $\begin{array}{l}\text { Reação a Concorrencia em } \\
\text { mercados Intl }\end{array}$ & & & & \\
\hline \multirow{6}{*}{ 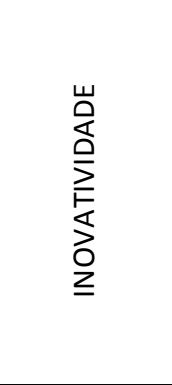 } & Criatividade Internacional & & & & \\
\hline & Diferenciação internacional & & & & \\
\hline & \begin{tabular}{|l|} 
Novos produtos para \\
mercados internacionais
\end{tabular} & & & & \\
\hline & Pessoas & & & & \\
\hline & $\begin{array}{l}\text { Processos de inovação para } \\
\text { atuar em mercados } \\
\text { internacionais }\end{array}$ & & & & \\
\hline & Recursos Financeiros & & & & \\
\hline \multirow{4}{*}{ 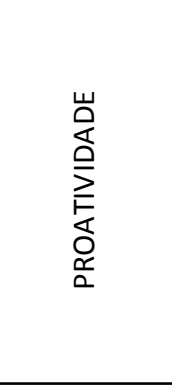 } & $\begin{array}{l}\text { Atitude de Antecipação } \\
\text { frente aos concorrentes }\end{array}$ & & & & \\
\hline & \begin{tabular}{|l} 
Flexibilidade tecnologica \\
para atuar em mercados intl
\end{tabular} & & & & \\
\hline & $\begin{array}{l}\text { Monitoramento do Ambiente } \\
\text { Intl }\end{array}$ & & & & \\
\hline & $\begin{array}{l}\text { Participação e resolução de } \\
\text { problemas para atender } \\
\text { mercados intl }\end{array}$ & & & & \\
\hline \multirow{4}{*}{$\begin{array}{l}\text { O } \\
\frac{\tilde{n}}{x}\end{array}$} & Risco em Negocios Intl & & & & \\
\hline & Risco Financeiro & & & & \\
\hline & Risco na decisão intl & & & & \\
\hline & Risco-geral & & & & \\
\hline
\end{tabular}

Legenda: 1) células azul-escuras = maior parte das categorias evocadas com maior ocorrência nas entrevistas; 2) células azul-claras = maior e menor partes das categorias relatadas com menor ocorrências nas entrevistas; 3) células brancas = menor partes das categorias evocadas com menor ocorrência nas entrevistas.

Lançando um olhar sobre a evolução dos elementos da base original de OE para o conjunto consolidado para a pesquisa, chama a atenção as dimensões Inovatividade e Proatividade, que tiveram o maior número de elementos intensificados, sendo as práticas que mais se destacaram nas organizações, de acordo com o relato dos gestores. As dimensões Assunção de Riscos e Agressividade Competitiva foram as que tiveram diversos elementos 
atenuados, o que sugere que as organizações percebem e apresentam alguns elementos melhor desenvolvidos que outros nas empresas amostradas, devido à experiência internacional e exposição à competição ao longo da trajetória de negócios internacionais de cada empresa, em relação a acesso ao mercado e formação de canais de vendas. A dimensão Autonomia destacase por ter o maior número de elementos atenuados, onde as categorias foram evocadas com relativa ocorrência e muita disparidade pelos entrevistados, sugerindo que faz sentido, e por isso, praticada de forma menos homogênea nas empresas do aerodesporto, o que não quer dizer que ela é menos praticada que as demais dimensões, entretanto a influência do porte das organizações e estratégias de gestão top-down evidenciam as diferenças entre as empresas e o alcance de suas decisões.

Segundo FREITAS et al., (2012), a importância de cada dimensão para predizer a natureza e o sucesso de um empreendimento, depende de fatores externos, fatores internos e das características dos líderes da organização, podendo a OE ser constituída por diferentes combinações das cinco dimensões, ou mesmo por apenas algumas delas. A seguir é feita uma breve abordagem sobre cada dimensão num contexto internacional.

A dimensão Inovatividade e apresenta categorias e elementos que são apontados pela literatura como práticas que caracterizam a $\mathrm{OE}$, conforme foi relatado pelos executivos das empresas entrevistadas:

"[...] foram mais de 40 produtos desde 2000 quando a gente trouxe o André (projetista) da Suíça, ele já tinha uma bagagem grande, a gente desenvolveu rápido, não é? Já começamos com parapente de competição, serviu de protótipos, parapente de escola, intermediário, não é? Em dois anos a gente já tinha um mix de produto que nem da Nova [...]" (Sol Parapentes);

A dimensão Assunção de Risco, para analisar as categorias e elementos do risco internacional, foi adaptado o modelo de Freitas et al. (2012) e adicionalmente o levantamento de Leite e Moraes (2014) completa o entendimento, considerando as empresas brasileiras:

“[...] eu acho que principal, em termos de processos principalmente a adaptação às normativas européias aí, né?! Se eu vou gastar aí 30, 40.000 reais numa homologação, quantos Conquest (produto pioneiro) eu tenho que vender pra pagar isso, né?! Mas aí também cara, com a redução do volume, com a crise, tudo mais, a gente parou também um pouco de investir [...]" (Tirante A);

A Proatividade deve ser considerada não apenas como uma forma sistemática de adaptação ambiental, mas de certa forma como a capacidade de reinvestimento da empresa em comparação aos rivais na mesma indústria (COVIN; WALES, 2012; GEORGE; MARINO, 2011; LUMPKIN; DESS, 2001).

“[...] sim, todos os competidores (locais) da gente não estão a nossa altura, porque nenhum é certificado e nenhum é regulamentado. Então nós estamos $100 \%$ do mercado, somos a única empresa registrada na Aeronáutica [...]" (Trike Icaros);

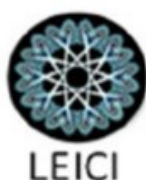


A dimensão agressividade competitiva, para analisar as categorias foi utilizada a discussão de Lumpkin e Dess (1996; 2001), que trata a dimensão como reação a ameaças, resumidamente como respostas às ações da concorrência, denominando-a como responsividade (COVIN; LUMPKIN, 2011; MARTENS; FREITAS, 2008):

“[...] a gente combate, a gente sofre no Brasil, por exemplo, alguma agressividade da concorrência, novos entrantes, não é? Ah, vamos fazer defesa comercial, ele manda direto da China via correio para a casa do consumidor, aí, daí entra mais barato, não sei o quê, só faz estrago. Só que esse é um canal que não se propaga, entende? Não é assim, a gente já teve marcas que estão saindo do mercado agora, não é? Nos últimos dez anos teve cinco marcas que já fizeram bastante alarido, não é? E que agora não são nem desejadas mais no mercado, elas conseguem vender direto, vender fora da escola, mas não acompanham. Ontem eu falava com uma empresa, todo mundo dá três meses de garantia, não é? Meu fornecedor dá seis meses, dá o dobro do tempo de garantia [...]" (Sol Paragliders);

A dimensão autonomia, seguiu-se estudos que citam o pensamento empreendedor como encorajador de ações independentes e de autodesenvolvimento, conforme os estudos de Freitas et al. (2012). O comportamento autônomo internacional refere-se à medida que uma empresa permite que seu pessoal adote ações independentes destinadas a produzir novas ideias, novos produtos e darem destino comercial às atividades (LUMPKIN, 2005):

"[...] na verdade, não. Eu trabalhava sozinho. Trabalhava a minha ex-mulher trabalhava comigo, não na parte de produção, ela trabalhava na parte de financeiro, compra e agora nós três (filhos) estamos na fábrica. A gente tem uns dealers super fortes lá fora, mas eu fui lá e voltei com onze encomendas. Então você vê que o tête-à-tête nosso é bom. E a princípio meus dealers eram brasileiros, agora está mudando isso, tem mais gringos [...]" (Rotor Harnesses);

\section{Considerações Finais}

Neste estudo, houveram diferenças significativas nos desempenhos entre as organizações: a maior empresa e mais estabelecida apresentou melhor desempenho em termos de exibição das dimensões da OEI do que suas homólogas menos internacionalizadas em todas as medidas. Isso pode ser devido a estratégias de posicionamento com maior escopo e diversidade no número de representantes nos mercados internacionais, que por sua vez operam de forma flexível e com menores riscos no modo de entrada, mas exigem maiores esforços de gestão por parte da empresa. O estudo resulta em linha com autores nacionais quando resumem que, de uma maneira geral, a literatura sugere que uma maior OE contribui com a performance nas empresas participantes neste estudo, tanto no mercado local como internacionalmente, de empresas novas ou já estabelecidas (FREITAS et al., 2012).

Por fim, o foco se move para um tópico além do examinado em Knight e Cavusgil (2004): o papel do indivíduo na internacionalização empresarial. A importância da pesquisa sobre o empreendedor é sinalizada na retrospectiva de Cavusgil e Knight (2015), que reitera o
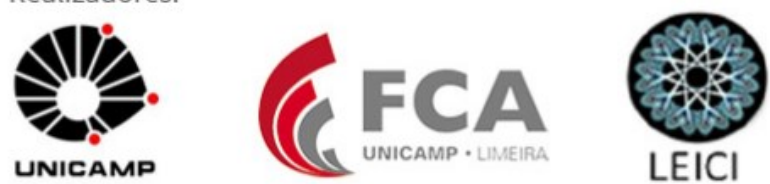
argumento de Jones e Coviello (2005), segundo o qual a intenção e a atitude do empreendedor merecem atenção. Chamadas semelhantes para aumentar a compreensão sobre o empreendedor são feitas por Autio (2005) e Zahra (2005) em seus comentários sobre Oviatt e McDougall (1994).

Como tal, pode haver um ponto de pesquisa que relacione os estudos de psicologia e administração, por exemplo quando Vissak (2010) lembra que a pesquisa sobre INV não explica geralmente a escolha dos modos de entrada ou os estágios de desenvolvimento após o início das ações de exportação, sendo que os estudos encontrados na literatura recente, tende a assumir que os empreendedores se comportam e atuam de forma semelhante, apesar da diversidade geográfica das operações comerciais, e assim demonstrar que tais fenômenos não se limitam a uma única indústria, tamanho da empresa, tipo de propriedade ou idade, proprietários diferentes e padrões de internacionalização.

Duas principais implicações para os gestores praticantes podem ser destacadas, considerando as empresas do aerodesporto nacional. Em primeiro lugar, pode se notar que a partir dos resultados do estudo, neste caso, que o comportamento empreendedor não tem efeito sobre a estratégia internacional de tipo $\mathrm{BG}$, no sentido de que estão mais próximas da classificação de INV e sustentam estratégias de diferenciação com características regionais e de certa aversão ao risco, focados nos clientes finais como nicho. No entanto, parece que certos tipos de comportamento empreendedor são mais importantes do que outros em diferentes estágios do ciclo de vida da empresa. E a segunda implicação, considerando a noção de $\mathrm{OE}$ resumida no estudo, é que, em contraste, atitudes dos gerentes, no geral, não explicam a diversidade global nesta pesquisa, se focada em novos empreendimentos baseados em tecnologia como mais tomadores de risco para a exibição e operacionalização de uma OEI, como a maioria dos estudos considerados para esta pesquisa trazem conclusivamente.

\section{Referencias}

ASPELUND, Arild; MADSEN, Tage; MOEN, Øystein. A review of the foundation, international marketing strategies, and performance of international new ventures. European Journal of Marketing, v. 41, n. 11/12, p. 1423-1448, 2007.

AUTIO, Erkko; SAPIENZA, Harry J.; ARHENEUS, James G. Effects of age at entry, knowledge intensity, and imitability on international growth. Academy of management journal, v. 43, n. 5, p. 909-924, 2000.

BARRETO, J. C.; NASSIF, V. M. J. O Empreendedor Líder E a Disseminação Da Orientação Empreendedora. Revista Brasileira de Gestao de Negocios, v. 16, n. 51, p. 180-198, 2014.

CAVUSGIL, S. T.; KNIGHT, G. The born global firm: An entrepreneurial and capabilities perspective on early and rapid internationalization. Journal of International Business Studies, v. 46, n. 1, p. 3-16, 2015.

COVIELLO, N. Re-thinking research on born globals. Journal of International Business Studies, v. 46, n. 1, p. 17-26, 2015.

COVIELLO, N. E.; JONES, M. V. Methodological issues in international entrepreneurship research. Journal of Business Venturing, v. 19, n. 4, p. 485-508, 2004.

COVIN, J. G.; LUMPKIN, G. T. Entrepreneurial orientation theory and research: Reflections on a needed construct. Entrepreneurship: Theory and Practice, v. 35, n. 5, p. 855-872, 2011.

COVIN, J. G.; MILLER, D. International Entrepreneurial Orientation: Conceptual Considerations, Research Themes, Measurement Issues, and Future Research Directions. Entrepreneurship: Theory and Practice, v. 38, n. 1, p. $11-44,2014$.
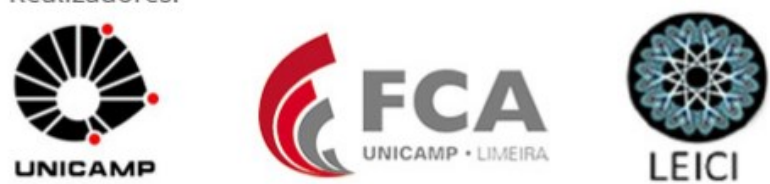
COVIN, J. G.; WALES, W. J. The Measurement of Entrepreneurial Orientation. Entrepreneurship: Theory and Practice, v. 36, n. 4, p. 677-702, 2012.

GIL, A. C.; LICHT, R. H. G.; OliVA, E. D. C. a Utilização De Estudos De Caso Na Pesquisa Em Administração. Revista Base (Administração e Contabilidade) da UNISINOS, v. 2, n. 1, p. 11, 2005.

GODOY, A. S. Introdução à pesquisa qualitativa e suas possibilidades. Revista de Administração de Empresas, v. 35, n. 2 , p. $57-63,1995$.

HONÓRIO, Luiz Carlos. Determinantes organizacionais e estratégicos do grau de internacionalização de empresas brasileiras. RAE-revista de administração de empresas, v. 49, n. 2, 2009.

JOHANSON, J. VAHLNE. The internationalization process of the firm: A model of knowledge development and increasing foreign market... Journal of International Business Studies, 2002.

KNIGHT, G. A.; KIM, D. International business competence and the contemporary firm. Journal of International Business Studies, v. 40, n. 2, p. 255-273, 2009.

KUIVALAINEN, O; SUNDQVIST, S.; SERVAIS, P. Firms' degree of born-globalness, international entrepreneurial orientation and export performance. Journal of World Business, v. 42, n. 3, p. 253-267, 2007.

LAGE, M. C.; GODOY, A. S. O uso do computador na análise de dados qualitativos: questões emergentes. RAM. Revista de Administração Mackenzie, v. 9, n. 4, p. 75-98, 2008.

LEITE, Y. V.; DE MORAES, W. A. As Dimensões do Empreendedorismo Internacional: Uma Proposição de um Framework. Revista Ibero-Americana de Estratégia, v. 13, n. 4, p. 91-106, 2014.

LUMPKIN, G. T.; DESS, G. G. Linking two dimensions of entrepreneurial orientation to firm performance: The moderating role of environment and industry life cycle. Journal of Business Venturing, v. 16, n. 5, p. 429-451, 2001.

MARTENS, C. D. P. et al. Research on entrepreneurial orientation: current status and future agenda. International Journal of Entrepreneurial Behavior \& Research, v. 22, n. 4, p. 556-583, 2016.

MARTINS, G. A. Estudo De Caso: Uma Reflexão Sobre a Aplicabilidade Em Pesquisas No Brasil. RCO Revista de Contabilidade e Organizações - FEARP/USP, v. 2, p. 8-18, 2008.

MATLAY, H. et al. SME internationalization research: Past, present, and future. Journal of Small Business and Enterprise Development, v. 13, n. 4, p. 476-497, 2006.

MOZZATO, A. R.; GRZYBOVSKI, D.; TEIXEIRA, A. N. Análises Qualitativas Nos Estudos Organizacionais: As Vantagens No Uso Do Software Nvivo ®. v. 23, p. 578-588, 2016.

OVIATT, B. M.; MCDOUGALL, P. P. The internationalization of entrepreneurship. Journal of International Business Studies, v. 36, n. 1, p. 2-8, 2005.

ROWDEN, Robert W. Research Note: How a small business enters the international market. Thunderbird International Business Review, v. 43, n. 2, p. 257-268, 2001.

SHANE, S.; VENKATARAMAN, S. The promise of entrepreneurship as a field of research. Entrepreneurship: Concepts, Theory and Perspective, v. 25, n. 1, p. 171-184, 2007.

SLEVIN, D. P.; TERJESEN, S. A. Entrepreneurial orientation: Reviewing three papers and implications for further theoretical and methodological development. Entrepreneurship: Theory and Practice, v. 35, n. 5, p. 973987, 2011.

TELLES, Renato. A efetividade da matriz de amarração de Mazzon nas pesquisas em Administração. Revista de Administração da Universidade de São Paulo, v. 36, n. 4, 2001.

ZAHRA, S. A.; COVIN, J. G. Contextual influences on the corporate entrepreneurship-performance relationship: A longitudinal analysis. Journal of Business Venturing, v. 10, n. 1, p. 43-58, 1995.

YIN, R.K. Estudo de Caso: Planejamento e Métodos. 3. ed. Porto Alegre: Bookman. 2005.

WACH, Krzysztof. Entrepreneurial orientation and business internationalisation process: The theoretical foundations of international entrepreneurship. Entrepreneurial Business and Economics Review, v. 3, n. 2 , p. 9 24, 2015.

WALES, William John. Entrepreneurial orientation: A review and synthesis of promising research directions. International Small Business Journal, v. 34, n. 1, p. 3-15, 2016. 